\title{
Reconsidering the Indirect Dependency Approach to Wh-Scope Marking
}

\author{
Andreas Haida \\ ZAS, Berlin
}

\section{Introduction}

\subsection{Wh-scope Marking Questions}

In this paper, I will present a novel semantic analysis of so-called wh-scope marking (WSM) questions. WSM questions are complex sentences expressing a longdistance $w h$-question by means of two (or more) interdependent $w$ h-clauses. In (1), you find examples of such questions from German and Russian.

(1) a. $\left[\mathrm{CP}_{1}\right.$ Was glaubst du $\left[\mathrm{CP}_{2}\right.$ wen Hans liebt $\left.]\right]$ ?

(German) what think you whom Hans loves

'Who do you think that Hans loves?'

b. $\left[\mathrm{CP}_{1}\right.$ Kak vy dumaete $\left[\mathrm{CP}_{2}\right.$ kogo ljubit Ivan $\left.]\right]$ ?

(Russian) how you think whom loves Ivan

'Who do you think that Ivan loves?'

Above and in the following, the superordinate clause of a WSM question and its (immediately) subordinate clause are designated $\mathrm{CP}_{1}$ and $\mathrm{CP}_{2}$, respectively. Furthermore, the $w h$-word of $\mathrm{CP}_{1}$ is referred to by the (descriptive) term "wh-scope marker" and the $w h$-word of $\mathrm{CP}_{2}$ by "true wh-word."

The peculiarity of WSM questions can be described most concisely by tracing the basic assumptions of the first analyses they have received (van Riemsdijk 1983, McDaniel 1989): The answerhood conditions of (1a,b), as reflected by their English paraphrases, suggest that the true $w h$-word is interpreted with matrix scope, whereas the $w h$-scope marker does not receive an interpretation at all. This gave rise to the assumption that the $w h$-scope marker is not a contentful $w h$-word but a $w h$ expletive marking the scope of the true $w h$-word (hence its name). Furthermore, the presence of the $w h$-expletive in Spec- $\mathrm{CP}_{1}$ was assumed to allow the true $w h$-word to reside in the specifier of $\mathrm{CP}_{2}$ even though the matrix verbs of $(1 \mathrm{a}, \mathrm{b})$ do not select interrogative complements. ${ }^{1}$

\footnotetext{
I am grateful to the audiences of SALT XVII and SemNet 7 for their helpful comments. I owe special thanks to Veneeta Dayal, Benjamin Spector, and Ede Zimmermann for the additional feedback they gave me. Furthermore, I would like to thank Penka Stateva, Peter Staudacher, and Arthur Stepanov for raising my interest in WSM questions.

${ }^{1}$ In German, this is shown by the ungrammaticality of the following construction.

(i) * Ich glaube, wen Hans liebt.

I think whom Hans loves

(German) 
For reasons of space, I will not go into the analyses departing from these assumptions. Let me just mention that they involve a direct syntactic dependency between the $w h$-scope marker and the true $w h$-word. This property distinguishes these analyses from the approach that will be discussed in this paper, the so-called indirect dependency approach (IDA). The IDA, proposed in its original form by Dayal (1994), overcomes the construction-specific assumptions of the former analyses and thereby greatly improves the understanding of the syntax and semantics of WSM questions. Since my analysis is a variant of the IDA, Dayal's original approach will be briefly sketched in the following subsection.

\subsection{Dayal's Indirect Dependency Approach}

The IDA proposed by Dayal (1994) shares with the previous analyses the assumption that the $w h$-scope marker has a syntactic correlate. However, the correlate is not the true $w h$-word but the subordinate clause, $\mathrm{CP}_{2}$. Thus, there is only an indirect dependency between the $w h$-scope marker and the true $w h$-word. This is shown in (2) with the structure assumed by Dayal (1994) for sentences like (1a). Observe that the $w h$-scope marker is coindexed with the subordinate clause $\mathrm{CP}_{2}$.

$$
\begin{array}{r}
{\left[\mathrm{CP}_{1}\left[\mathrm{CP}_{1} \text { was }_{2} \mathrm{C}_{1}{ }^{[+\mathrm{Q}]}\left[\mathrm{IP} \text { du [vP } t_{\text {was }_{2}} \text { glaubst }\right]\right]\right]} \\
\left.\left[\mathrm{CP}_{2} \text { wen } \mathrm{C}_{2}{ }^{[+\mathrm{Q}]}\left[\text { Hans } t_{\text {wen }} \text { liebt }\right]\right]\right]
\end{array}
$$

Some other properties of (2) are characteristic of Dayal's IDA: $\mathrm{CP}_{2}$ is headed by the interrogative complementizer $\mathrm{C}^{[+\mathrm{Q}]}$. Hence, the movement of the true $w h$-word to the specifier of $\mathrm{CP}_{2}$ is an instance of ordinary wh-movement. However, as an interrogative clause, $\mathrm{CP}_{2}$ does not satisfy the selectional restrictions of the superordinate verb. Therefore, $\mathrm{CP}_{2}$ is assumed to be an adjunct to $\mathrm{CP}_{1}{ }^{2}$ The complement position of the superordinate verb is occupied by the wh-scope marker, which is base-generated in this positition and subsequently moves to the specifier of $\mathrm{CP}_{1}$. Thus, the $w h$-scope marker is an ordinary $w h$-word.

The indirect syntactic dependency between the $w h$-scope marker and the true $w h$-word is a necessary condition for the realization of the interpretive connection that exists between these question words. According to Dayal (1994), this connection is established essentially by standard semantic means. ${ }^{3}$ Following the Hamblin/Karttunen approach to the semantics of questions (Hamblin 1973, Karttunen 1977), interrogative clauses are assumed to denote sets of propositions. The basic idea of Dayal's IDA, then, is that the $w h$-scope marker is a question word that asks for propositions, and that $\mathrm{CP}_{2}$ denotes a restriction on the admissible propositions. Accordingly, the $w h$-scope marker is analyzed as a generalized quantifier over propositions. This is shown in (3) with the denotation of was $_{2}$. Note that

\footnotetext{
${ }^{2}$ Alternatively, $\mathrm{CP}_{2}$ can be an IP adjunct. However, this syntactic option does not lead to an intelligible semantic result (see Dayal 1994: p. 157, fn. 10.). Therefore, it will be ignored in the following.

${ }^{3}$ But see Beck and Berman (2000) for a critique of some of Dayal's semantic assumtpions.
} 
the index of the $w h$-scope marker and hence the index of the subordinate clause is passed on to the restriction variable $T_{2}$.

$$
\lambda Q \cdot \exists q\left(T_{2}(q) \wedge Q(q)\right)
$$

The representation in (4) shows how the denotation of (the lower segment of) $\mathrm{CP}_{1}$ of (2) is derived by composing this quantifier with the sister of the moved scope marker. As a result of this semantic compositon, $\mathrm{CP}_{1}$ denotes a question over the propositions the hearer believes.

(4)

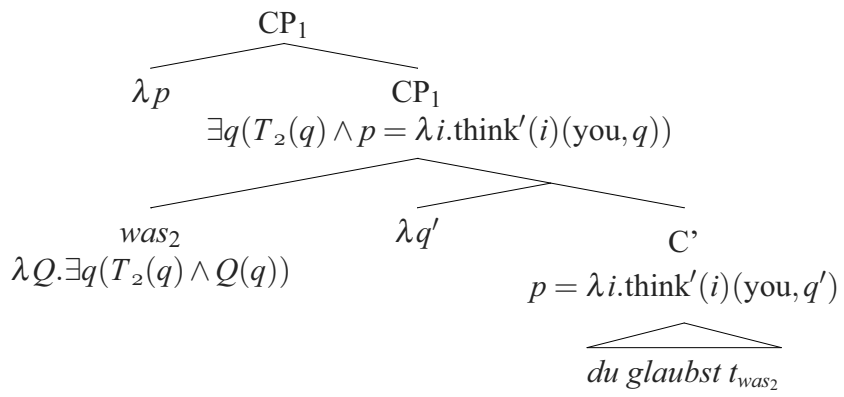

The semantic composition proceeds by $\lambda$-abstracting the restriction variable $T_{2}$ in the denotation of $\mathrm{CP}_{1}$. This makes it possible to compose the denotation of $\mathrm{CP}_{1}$ with $\mathrm{CP}_{2}$, as is shown in (5).

(5)

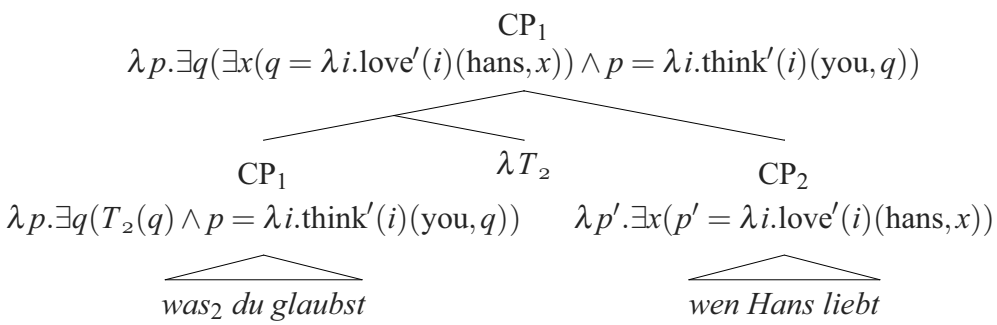

Hence, according to Dayal's IDA (1a) is a question over the propositions the hearer believes, where these propositions are of the form Hans loves $x$ (for some entity $x$ ). This is an intuitively correct result. Still, Dayal's IDA can be improved in several syntactic and semantic aspects, as will be shown in the following sections.

\section{Reconsidering the IDA}

\subsection{A Revised Syntactic Analysis}

In this and the following section, I will show that we can improve on Dayal's IDA by applying the partition theory of questions (Groenendijk and Stokhof 1982) to the syntactic analysis of WSM questions proposed by Herburger (1994) and Stepanov 
(2000). According to these proposals, the WSM question in (1b) has the structure in (6) at Spell-Out. ${ }^{4}$

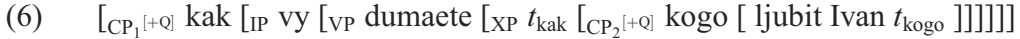

The representation in (6) shows two characteristics of the IDA: (i) The $w h$-scope marker kak and the true $w h$-phrase kogo participate in two unrelated chains and (ii) $\mathrm{CP}_{2}$ is an interrogative clause. What is specific to this version of the IDA is the assumption that (the trace of) the $w h$-scope marker and $\mathrm{CP}_{2}$ form a constituent, $\mathrm{XP}$, which functions as the complement of the superordinate verb. This assumption is well supported by syntactic evidence pertaining to case and movement theory (see also Stepanov and Stateva 2006).

Besides this evidence, there are other arguments in favor of the revised IDA syntax. For example, the wh-scope marker locally c-commands $\mathrm{CP}_{2}$ in its base position in XP. This makes it possible to account for certain morphosyntactic constraints on $\mathrm{CP}_{2}$. A case in point is the well-known fact that in some languages, $\mathrm{CP}_{2}$ cannot be a yes/no or alternative question. German is such a language, as can be seen by the deviance of the WSM constructions in (7).
a. * Was glaubst du, ob Hans kommt? what think you whether Hans comes
b. * Was glaubst du, ob Hans oder Franz kommt? what think you whether Hans or Franz comes

(German)

The revised IDA syntax can account for this deviance with the assumption that the German $w h$-scope marker must enter into an Agree relation with a wh-phrase in its local c-command domain. ${ }^{5}$ This requirement rules out non-wh clauses in

\footnotetext{
${ }^{4}$ Here, I consider the Russian example because Russian allows for a particularly simple syntactic analysis. In OV-languages like German and Hindi, matters are more complicated since we still find $\mathrm{CP}_{2}$ to the right of the matrix predicate (and the verbal cluster in general). See (i) for a German example.

(i) Was hat Hans sagen sollen, wen er liebt? what has Hans say be to whom he loves

(German)

'Who was Hans to say that he loves?'

To account for the linear order between $\mathrm{CP}_{2}$ and the verbal cluster, we can assume that XP is extraposed to IP. This is shown in (ii) with a simplified structure for (i). (The $w h$-scope marker presumably moves successive-cyclically to the left edge of the verbal domain before extraposition applies. This is not represented below.)

(ii) $\left[\mathrm{CP}_{1}\right.$ was hat $\left[\mathrm{IP}\left[\mathrm{IP}\right.\right.$ Hans $\left[\mathrm{I},\left[\mathrm{VP}\left[\mathrm{VP} t_{\mathrm{XP}}\right.\right.\right.$ sagen $]$ sollen $\left.\left.] t_{\mathrm{hat}}\right]\right]\left[\mathrm{XP} t_{\mathrm{was}}\left[\mathrm{CP}_{2}\right.\right.$ wen er liebt $\left.\left.]\right]\right]$

Furthermore, note that the extraposed XP must be reconstructed at LF.

${ }^{5}$ The so-called $w$-copy construction of German (and other languages) provides further evidence for such an agree relation. Sentences like (i) are often assumed to contain multiple copies of a single $w h$-phrase at intermediate positions of successive cyclic $w h$-movement.
}

(i) Wen glaubst du, wen Hans liebt?

(German)

Whom think you whom Hans loves

'Who do you think that Hans loves?' 
German WSM questions (see Fanselow and Mahajan 2000: 214ff for a discussion of a broader range of data from much the same point of view).

The deviance of $(7 a, b)$ cannot be explained in a principled way on the basis of the syntactic assumptions of the original IDA. For reasons like this, Dayal (2000) envisages adopting the revised syntax, at least, for languages like German. The compatibility of Dayal's semantic approach with the revised syntax is shown in Stepanov (2000) with an explicit compositional analysis.

\subsection{The Partition-Theoretic IDA}

The basic idea of the semantic analysis I am proposing can be described as follows. From a semantic point of view, it is natural to assume that the formation of XP is the syntactic reflex of a type mismatch that is characteristic of WSM questions: The superordinate verb s-selects a proposition, that is, a semantic object of type st. The embedded CP, however, denotes a question - an object of type $\langle s, s t\rangle$, if we follow Groenendijk and Stokhof (1982). Therefore, if the XP shell serves to resolve this type mismatch, the trace of the $w h$-scope marker must be of type $s$ (assuming the smallest possible type). This means that the type relations within the matrix VP of (6) are as depicted in (8).

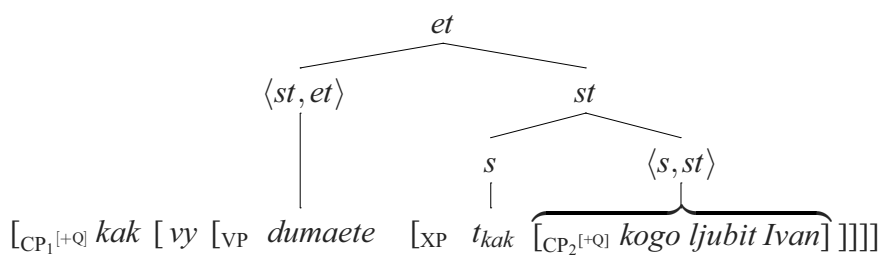

In the remainder of this paper, I will show that the type assumptions made above lead to a very satisfactory account of the semantics of WSM questions. To begin with, I will briefly describe what semantics we arrive at if we translate these type assumptions into semantic representations in accordance with Groenendijk and Stokhof (1982). ${ }^{6}$ To do this, we first have to specify the structure of the left periphery of (6), namely as given in (9).

However, it is more plausible that the alleged higher copy of wen 'whom' is in fact a wh-scope marker. This amounts to assuming that (i) has the structure in (ii).

(ii) $\left[\mathrm{CP}_{1}{ }^{[+\mathrm{Q}]}\right.$ wen 1 glaubst du $\left[\mathrm{XP} t_{\mathrm{wen}_{1}}\left[\mathrm{CP}_{2}[+\mathrm{Q}]\right.\right.$ wen 2 Hans $t_{\mathrm{wen}_{2}}$ liebt $\left.\left.]\right]\right]$

The configuration in (ii) allows the $w h$-scope marker $w_{e n}$ to agree with the true $w h$-word $w_{2}$, the matched features being accusative case, $[+w h]$, and [+human]. This analysis is more in line with the fact that the $w h$-copy construction is restricted to non-phrasal wh-constituents:

(iii) * Welche Frau glaubst du, welche Frau Hans liebt?

(German) which woman think you which woman Hans loves

I am grateful to Arthur Stepanov for pointing this out to me.

${ }^{6}$ However, I will abstract away from the grammar theory this work is based on, namely Montague grammar. 


$$
\begin{aligned}
& {\left[\mathrm { CP } _ { 1 } \mathrm { C } _ { 1 } { } ^ { [ + \mathrm { Q } ] } \left[\mathrm { FocP } _ { 1 } \text { kak } \left[\mathrm { IP } \text { vy } \left[\mathrm { vP } \text { dumaete } \left[\mathrm { XP } t _ { \mathrm { kak } } \left[\mathrm{CP}_{2} \mathrm{C}_{2}{ }^{[+\mathrm{Q}]}\right.\right.\right.\right.\right.\right.} \\
& \text { [FocP } 2 \text { kogo ljubit Ivan } t_{\text {kogo }} \text { ]]]]]]] }
\end{aligned}
$$

In (9), the $w h$-scope marker and the true wh-phrase occupy the specifier position of a projection selected by $\mathrm{C}$. For the sake of concreteness, this projection is assumed to be FocP (cf. Stepanov 1998). In the following, I assume that (9) is the LF representation of (1b).

According to Groenendijk and Stokhof (1982), a wh-chain headed by an argument $w h$-phrase translates as a $\lambda$-abstract of type et (in the simplest case of only one $w h$-dependency). This is schematically exemplifed in (10a) for the true wh-phrase of (9). If we make the corresponding assumption for the chain headed by the $w h$-scope marker, we must translate this chain as shown in (10b).

$$
\begin{aligned}
& \text { a. }\left[\operatorname{kogo}\left[\ldots t_{k o g o} \ldots\right]\right] \leadsto \lambda x(\ldots x \ldots), \text { where } x \text { is a variable of type } e \\
& \text { b. }\left[\operatorname{kak}\left[\ldots t_{k a k} \ldots\right]\right] \leadsto \lambda k(\ldots k \ldots), \text { where } k \text { is a variable of type } s
\end{aligned}
$$

Now assume that the interrogative complementizer $\mathrm{C}^{[+\mathrm{Q}]}$ denotes the operator $\mathbf{Q}$ defined in (11).

$$
\mathbf{Q}(\alpha):=\lambda i \lambda j(\alpha=[\lambda i . \alpha](j)), \quad \text { where } \alpha \text { is of relational type }
$$

According to these assumptions, (9) denotes the semantic object given in (12) - a propositional concept, as will become evident immediately below.

$$
\mathbf{Q}\left(\lambda k \cdot \operatorname{think}^{\prime}(i)\left(\text { you, }\left[\mathbf{Q}\left(\lambda x \cdot \operatorname{love}^{\prime}(i)(\operatorname{ivan}, x)\right)\right](k)\right)\right)
$$

By the definition of $\mathbf{Q}$ and by variable renaming, we can rewrite (12) as follows.

$$
\begin{aligned}
& \lambda i \lambda j\left(\lambda k \cdot \operatorname{think}^{\prime}(i)\left(\operatorname{you}, \lambda l\left(\lambda x \cdot \operatorname{love}^{\prime}(k)(\operatorname{ivan}, x)=\lambda x \cdot \operatorname{love}^{\prime}(l)(\operatorname{ivan}, x)\right)\right)=\right. \\
& \left.=\lambda k \cdot \operatorname{think}^{\prime}(j)\left(\operatorname{you}, \lambda l\left(\lambda x \cdot \operatorname{love}^{\prime}(k)(\operatorname{ivan}, x)=\lambda x \cdot \operatorname{love}^{\prime}(l)(\operatorname{ivan}, x)\right)\right)\right)
\end{aligned}
$$

For reasons of space, I will not discuss the details of the semantic composition of $\left(12^{\prime}\right)$. Instead, I will show in Section 3.3 how to compositionally derive an equivalent denotation from (9) along the lines of Kratzer and Shimoyama (2002).

\subsubsection{The Answerhood Conditions Derived by the Partition-Theoretic IDA}

Although it might not be obvious, it can be easily shown that $\left(12^{\prime}\right)$ correctly represents the answerhood conditions of ( $1 b)$ (see the Appendix for a proof). However, this requires us to make certain assumptions regarding the beliefs of the hearer (that is, of the referent of the matrix subject of $1 \mathrm{~b}$ ): (i) that (s)he believes a proposition that is an exhaustive answer to the question expressed by $\mathrm{CP}_{2}$ and (ii) that (s)he believes the logical consequences of this belief. The second assumption should not be controversial since we are dealing with an epistemic notion of belief and not with an empirical one. The first assumption, however, requires some discussion because it imposes an exhaustivity presupposition on the contexts in which WSM questions can be adequately used. ${ }^{7}$ In the case of (1b), the presupposition imposed is only

\footnotetext{
${ }^{7}$ Many thanks to Benjamin Spector and Ede Zimmermann for making me aware of this.
} 
satisfied if there is no person for which the hearer doubts whether Ivan loves this person or not (at each possible world index). ${ }^{8}$ This presupposition is very hard to detect, if it exists at all.

Before trying to solve this problem, let me point out that exhaustivity presuppositions like the one noted above arise in the framework of Groenendijk and Stokhof (1982) with interrogatives other that WSM questions. Consider, for example, the matrix pair-list reading of the question in (13-Q), that is, the reading evoking answers like (13-A).

Q: Who said what who bought?

A: John said what Mary bought, Lucie said what Peter bought, ...

According to Groenendijk and Stokhof (1982), this reading is represented by the term in (14) (where a denotes the index of the actual world).

$$
\mathbf{Q}\left(\lambda x \lambda y \cdot \operatorname{say}^{\prime}(i)\left(x,\left[\mathbf{Q}\left(\lambda z \cdot \operatorname{buy}^{\prime}(i)(y, z)\right)\right](\mathrm{a})\right)\right)
$$

What we find is that (14) imposes the presupposition that for each answer pair $\langle x, y\rangle$, there is no $z$ such that $x$ remained silent about whether $y$ bought $z$ or not. Again, this presupposition seems not to be detectable, if it exists at all. Hence, if the exhaustivity presupposition imposed by $\left(12^{\prime}\right)$ turns out to be too problematic, a solution should be sought in the underlying question semantics and not in the specific approach to the semantics of WSM questions (see below). ${ }^{9}$

A radical solution would be to give up the strong exhaustivity of the question semantics of Groenendijk and Stokhof and to resort to a weakly exhaustive variant of this semantics. ${ }^{10}$ Along the lines of the prior analysis, this can be achieved with the question operator $\mathbf{Q}_{\mathrm{w}(\mathrm{eak})}$ defined in (15).

$$
\mathbf{Q}_{\mathrm{w}}(\alpha):=\lambda i \lambda j(\alpha \subseteq[\lambda i . \alpha](j)), \quad \text { where } \alpha \text { is of relational type }
$$

Clearly, this would eliminate the presuppositions discussed above. To keep matters simple, I will still use Groenendijk and Stokhof's original semantics in the follow-

\footnotetext{
${ }^{8}$ See Staudacher (2002) for this observation with regard to a semantic representation equivalent to $\left(12^{\prime}\right)$. Staudacher's analysis will be briefly sketched in Section 2.2.2.

${ }^{9} \mathrm{~A}$ factor that could be relevant for deciding how much of a problem the exhaustivity presupposition poses is the observation that the exhaustivity presupposition does not exclude the possibility for WSM questions to be only partially answered. That is, the proposition I think that Ivan loves Masha (among others) still counts as a partial answer to the semantic question given by $\left(12^{\prime}\right)$. See (i) for a definition that corresponds to the standard definition of the notion of partial answerhood (cf. Groenendijk and Stokhof 1984).

(i) A proposition $p$ is a partial answer to a question $Q$ iff there are indices $i_{1}, \ldots, i_{n}(n \geq 1)$ such that $p=Q\left(i_{1}\right) \vee \ldots \vee Q\left(i_{n}\right)$

Therefore, we could speculate that the exhaustivity presupposition does not show because it is overlaid by the pragmatics of question answering.

${ }^{10} \mathrm{~A}$ less radical way to deal with the exhaustivity presupposition might be to assume that each possible world has its own domain of entities (some of the consequences of this assumption are discussed in Groenendijk and Stokhof 1994). On this assumption, the exhaustivity presupposition is always satisfied with respect to a subset of the believe worlds of the hearer of a question like (1b). However, it requires further investigation to evaluate this possibility.
} 
ing. Note that all of the arguments presented below remain intact when switching to the weakly exhaustive variant. ${ }^{11}$

\subsubsection{How the Partition-Theoretic IDA Relates to the Original IDA}

The partition-theoretic IDA I am proposing is not just a translation of the original IDA into the semantic framework of Groenendijk and Stokhof (1982). In the partition-theoretic IDA, the $w h$-scope marker is a question word for possible worlds. By a simple translation of the original IDA, the $w h$-scope marker is analyzed as a question word for propositions (see Staudacher 2002). That is, the lower segment of $\mathrm{CP}_{1}$ of (2) receives the interpretation shown in (16) (ignoring for the moment the restriction on $p$ ).

(16) $\mathbf{Q}\left(\lambda p \cdot\right.$ think $^{\prime}(i)($ you, $\left.p)\right)$, where $p$ is a variable of type $s t$

Following the original IDA, the propositions $p$ believed by the hearer must be restricted to certain propositions, namely to the possible answers to $\mathrm{CP}_{2}$. This is achieved by adding to (16) the conjunct leading to (17).

$$
\begin{array}{r}
\mathbf{Q}\left(\lambda p\left(\exists k\left(p=T_{2}(k)\right) \wedge \text { think }^{\prime}(i)(\mathrm{you}, p)\right)\right), \text { where } T_{2} \text { and } k \text { are variables of } \\
\text { type }\langle s, s t\rangle \text { and } s, \text { respectively }
\end{array}
$$

By substituting $T_{2}$ with the denotation of $\mathrm{CP}_{2}$ of (2), we then arrive at the semantic representation shown in (18).

$$
\mathbf{Q}\left(\lambda p\left(\exists k\left(p=\left[\mathbf{Q}\left(\lambda x \cdot \operatorname{love}^{\prime}(i)(\text { hans }, x)\right)\right](k)\right) \wedge \operatorname{think}^{\prime}(i)(\text { you, } p)\right)\right)
$$

The propositional concept denoted by (18) is the Groenendijk\&Stokhof variant of the denotation derived in (5) by the original IDA. While (18) can be shown to be equivalent to (12) (ignoring, of course, the differing individual constants), ${ }^{12}$ the two representations differ considerably in their structure and hence lead to completely different compositional analyses. This shows that my variant of the IDA differs substantially from the original IDA and from Staudacher's partition-theoretic version of Dayal's approach.

\section{Advantages of the Partition-Theoretic IDA}

The partition-theoretic IDA has a number of advantages over Dayal's original approach.

\subsection{Binding-Theoretic Predictions}

Consider the German WSM question in (19).

\footnotetext{
${ }^{11}$ I am very grateful to Benjamin Spector for pointing this out to me.

${ }^{12} \mathrm{Cf}$. Staudacher 2002.
} 
(19) Was sagt er, wo Kai wohnt?

What says he where Kai lives

(German)

'Where does he say that Kai lives $t_{\text {where? }}$ '

According to the original IDA, the matrix subject of (19) does not c-command $\mathrm{CP}_{2}$ at LF (or at any other stage in the derivation) because $\mathrm{CP}_{2}$ is assumed to be an adjunct of $\mathrm{CP}_{1}$ (see 20).

$$
\begin{aligned}
& \text { Original IDA } \\
& \left.\left[\mathrm{CP}_{1}\left[\mathrm{CP}_{1} \text { was [ }\left[\mathrm{IP} \text { er [ } \mathrm{VP}_{\mathrm{w}} t_{\mathrm{was}} \text { sagt }\right]\right]\right]\left[\mathrm{CP}_{2} \text { wo Kai wohnt }\right]\right]
\end{aligned}
$$

This holds even if the original IDA is adapted to the revised syntax presented in Section 2.1 (see Stepanov 2000: for an explicit proposal): At LF, $\mathrm{CP}_{2}$ must be a sister of the $w h$-scope marker (or of a constituent dominating the scope marker) because their denotations must be composed with each other. Accordingly, Stepanov (2000) assumes the LF structure in (21).

$$
\begin{aligned}
& \text { Original IDA adapted to the revised syntax } \\
& \left.\left[\mathrm{CP}_{1}\left[\mathrm{XP} \text { was }\left[\mathrm{CP}_{2} \text { wo Kai wohnt }\right]\right]\left[\mathrm{IP} \text { er [ } \mathrm{VP} t_{\mathrm{XP}} \text { sagt }\right]\right]\right]
\end{aligned}
$$

In the partition-theoretic IDA, the c-command relations at LF differ crucially from those observed above. As can be seen in (22), the matrix subject c-commands $\mathrm{CP}_{2}$, and quite necessarily so because $\mathrm{CP}_{2}$ must be semantically composed with the superordinate verb.

\section{Partition-theoretic IDA}

[ $\mathrm{CP}_{1}$ was [IP $\operatorname{er}\left[\mathrm{VP}\left[\mathrm{XP} t_{\mathrm{was}}\left[\mathrm{CP}_{2}\right.\right.\right.$ wo Kai wohnt $\left.]\right]$ sagt $\left.\left.]\right]\right]$

Now observe that in (19), he and Kai cannot be interpreted as coreferent (cf. Fanselow and Mahajan 2000):

$$
\begin{aligned}
& \text { * Was sagt er } i \text { wo } \mathrm{Kai}_{i} \text { wohnt? } \\
& \text { What says he where Kai lives }
\end{aligned}
$$

(German)

On minimalist assumptions, LF is the only level relevant to binding conditions. Hence, Binding Theory cannot be used in the original IDA for explaining the deviance of (23) (even if adapted to the revised syntax). In contrast to this, the partition-theoretic IDA predicts a Condition $\mathrm{C}$ effect to emerge and hence the impossibility of the coreferent reading. Furthermore, representations like (12) are structurally suited to account for the Condition $\mathrm{C}$ effect observed above on purely semantic grounds (along the lines of Schlenker 2005).

Other relevant binding facts are hard to come by in WSM questions. If we consider, for example, quantifer binding, we encounter the intervention effect (see Beck 1996, Pafel 2000). That is, the only quantifiers that can occcur in the superordinate clause of a WSM question are arguably those that can outscope the wh-scope marker at LF (for discussion, see Krifka 2001). 


\subsection{Non-Factive Readings}

\subsubsection{Telling the Truth}

The German verb erzählen 'to tell' is non-factive. For example, we find that the sentence in (24) does not entail (or presuppose) that Maria lives in Paris.

(24) Kai hat erzählt, dass Maria in Paris wohnt.

Kai has told that Maria in Paris lives

(German)

'Kai told that Maria lives in Paris.'

However, as a question-embedding verb, erzählen receives a factive reading (cf. Karttunen 1977). That is, the sentence in (25) entails that Kai told the truth about where Maria lives.

(25) Kai hat erzählt, wo Maria wohnt.

(German)

Kai has told where Maria lives

'Kai told where Maria lives.'

According to Groenendijk and Stokhof (1984), the entailment of (25) is due to the fact that erzählen selects (what I call) the a-extension of a question. The a-extension of a question $\mathrm{Q}$ is the proposition $\llbracket \mathrm{Q} \rrbracket^{g}(\mathrm{a})$ : the exhaustive answer to $\mathrm{Q}$ at the index a of the actual world. According to this assumption, (25) denotes the proposition shown in (26).

$$
\lambda i . \text { tell }^{\prime}(i)\left(\text { kai, }\left[Q\left(\lambda x \text {.live_in }{ }^{\prime}(i)(\text { maria }, x)\right)\right](\mathrm{a})\right)
$$

Let us assume, for an example, that in the actual world, Maria lives only in Paris. Then (26) is the proposition that Kai told that Maria lives only in Paris.

\subsubsection{No factivity in WSM Questions}

Now note that in a WSM question, erzählen does not receive a factive reading (cf. Dayal 1994: pp. 163f):

(27) Ich weiss, was Kai erzählt hat, wo Maria wohnt.

I know what Kai told has, where Maria lives

(German)

'I know where Kai told that Maria lives.'

That is, (27) does not entail that Kai told the truth about where Maria lives. This is predicted by the partition-theoretic IDA. According to this approach, (27) denotes the propositional concept in (28).

$$
Q\left(\lambda k \text {.tell' }(i)\left(\text { kai, }\left[Q\left(\lambda x \text {.live_in }{ }^{\prime}(i)(\text { maria }, x)\right)\right](k)\right)\right)
$$

Observe that in (28) the index variable $k$ is $\lambda$-bound. Hence, $k$ does not (in general) denote the index of the actual world, and so no factive reading can arise.

In Dayal (1994), the readings noted above are accounted for by the distribution of the operator $A n s_{1}$ defined in (29). 


$$
A n s_{1}(Q):=\lambda p(p \in Q \wedge p(\mathrm{a}))
$$

However, the distribution of $A n s_{1}$ must be stipulated. That is, the term representing the unattested factive reading is semantically impeccable, as can be easily checked by considering (30).

$$
\begin{gathered}
\lambda p \cdot \exists q\left(A n s_{1}\left(\lambda p^{\prime} \cdot p^{\prime}=\lambda i \cdot \exists x\left(\text { live_in }^{\prime}(i)(\text { maria }, x)\right)\right)(q) \wedge\right. \\
\left.\wedge p=\lambda i \cdot \text { tell }^{\prime}(i)(\operatorname{kai}, q)\right)
\end{gathered}
$$

It is possible to evade this problem by replacing $A n s_{1}$ by an operator that cannot be applied to the subordinate clause of a WSM question. ${ }^{13}$ The operator $A n s_{2}$ defined in (31) is of this kind (see Dayal 1996: p. 116).

$$
\operatorname{Ans}_{2}(Q):=\imath p\left(p \in Q \wedge p(\mathrm{a}) \wedge \forall p^{\prime} \in Q\left(p^{\prime}(\mathrm{a}) \rightarrow p \subseteq p^{\prime}\right)\right)
$$

Still, the original IDA does not predict the lack of factive readings in WSM questions: The existence of $A n s_{1}$ shows that factive readings are not necessarily excluded like in the partition-theoretic IDA.

\subsubsection{No WSM with Factive Predicates}

In German, WSM does not occur with factive predicates like wissen 'to know' (cf. Dayal 1994):

$$
\begin{aligned}
& \text { * Was weiß Kai, wo Maria wohnt? } \\
& \text { what know Kai where Maria lives }
\end{aligned}
$$

(German)

Let us assume that the factivity of wissen is represented by means of the operator $\partial$ in the way specified in (33) (cf. Beaver 2001).

$$
\llbracket w i s s e n \rrbracket^{g}=\lambda i \lambda p \lambda x\left(\operatorname{know}^{\prime}(i)(x, p) \wedge \partial p(\mathrm{a})\right)
$$

Thereby, $\partial$ is the truth function defined in (34).

$$
\begin{array}{r|rrr}
v & 1 & 0 & n \\
\hline \partial v & 1 & n & n
\end{array}
$$

On this background, consider the denotation of (32) shown in (35).

$$
Q\left(\lambda k . \llbracket \text { wissen } \rrbracket^{g}(i)\left(\text { kai, }\left[Q\left(\lambda x \text {.live_in' }{ }^{\prime}(i)(\text { maria }, x)\right)\right](k)\right)\right)
$$

The term in (35) can be resolved as shown in (36) (unnecessary details omitted).

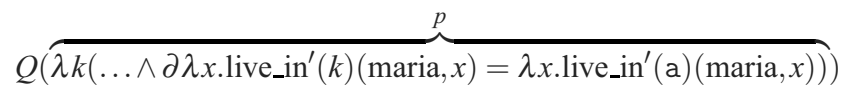

Now we can observe that for each index $\mathrm{k}, p(\mathrm{k}) \neq n$ iff Maria lives in the same places at $\mathrm{k}$ as at $\mathrm{a}$. This means that the denotation of (32) does not define a nontrivial partition of the set of indices and hence (32) does not denote a semantic question in the sense of the partition theory of questions. This shows that the partition theoretic IDA accounts for the unacceptability of (32).

\footnotetext{
${ }^{13}$ Many thanks to Chung-chieh Shan and Veneeta Dayal for making me aware of this.
} 


\subsection{Dealing with the Typological Diversity}

\subsubsection{WSM in wh-in-situ Languages}

WSM questions are found across the categories of the wh-typology. In the preceding sections, we have already discussed examples from $w$ h-ex-situ languages. For an example from a $w h$-in-situ language, consider the WSM question in (37) from Hindi (cf. Dayal 1994).

$$
\begin{aligned}
& \text { Ram-ne kyaa socaa ki ravii-ne kis-ko dekhaa? } \\
& \text { Ram-ERG what thought that Ravi-ERG who-ACC saw } \\
& \text { 'Who did Ram think that Ravi saw?' }
\end{aligned}
$$

(Hindi)

To provide a compositional analysis for (37), we have to clarify whether in-situ $w h$-phrases undergo covert $w h$-movement in Hindi. Crucial evidence for the LF position of in-situ wh-phrases is provided by constructions such as (38) (see Beck 2006).

$$
\begin{aligned}
& \text { ?? koi nahiiN kyaa paRhaa? } \\
& \text { anyone not what read.PERF.M } \\
& \text { intended: 'What did no one read?' }
\end{aligned}
$$

(Hindi)

The deviance of this construction is an example for a so-called wh-intervention effect. According to Pesetsky (2000), the deviance of (38) shows that the in-situ whphrase kyaa 'what' does not undergo covert phrasal wh-movement but only feature movement (which, acccording to Pesetsky, is blocked by the intervening negation, hence the deviance). In related work, Beck (2006) argues on semantic grounds that $w h$-intervention effects provide evidence for the in-situ interpretation of $i n$-situ wh-phrases.

Hence, it is reasonable to assume that the two $w h$-phrases in (37) remain in situ at LF. There are two versions of the partition theory that allow for the insitu interpretation of in-situ wh-phrases: Kratzer and Shimoyama (2002) and Haida (2005). For brevity, I will use the version of Kratzer and Shimoyama, which is sketched in the following subsection.

\subsubsection{Kratzer and Shimoyama's Version of the Partition Theory}

According to Kratzer and Shimoyama (2002), all constituents denote sets of ordinary denotations. More specifically, a non-wh word denotes the singleton set of its ordinary denotation. In contrast to this, wh-words denote (non-singleton) alternative sets. For example, the $w h$-pronoun who (and its cognates in other languages) denotes the set $\mathscr{E}$ of entities: ${ }^{14}$

$$
\llbracket w h o \rrbracket^{g}=\mathscr{E}
$$

\footnotetext{
${ }^{14}$ Here, I follow Groenendijk and Stokhof (1982) in the assumption that $w h$-pronouns do not have a domain restriction.
} 
The mode of composition is pointwise functional application. In interrogative sentences, the alternative sets of propositions resulting at the IP level are converted into singleton sets of question intensions in accordance with Groenendijk and Stokhof (1982). This is achieved by the question operator $\mathbf{Q}_{\mathrm{K} \& S}$ defined in (40).

$$
\llbracket \mathbf{Q}_{\mathrm{K} \& \mathrm{~S}} \alpha \rrbracket^{g}=\left\{\lambda i \lambda j . \forall p\left(p \in \llbracket \alpha \rrbracket^{g} \rightarrow(p(i) \leftrightarrow p(j))\right)\right\}
$$

The only additional assumption that must be made to derive the meaning of WSM questions concerns the denotation of $w h$-scope markers. As argued above, wh-scope markers are question words for possible worlds. In the semantic framework of Kratzer and Shimoyama, a wh-scope marker WSM must hence be assumed to denote the set $\mathscr{S}$ of indices:

$$
\llbracket \mathrm{wSM} \rrbracket^{g}=\mathscr{S}
$$

These assmptions will be used in the following subsections to give a compositional account of some of the WSM questions discussed in this paper.

\subsubsection{The in-situ Interpretation of in-situ wh-Scope Markers}

In (42), it is shown how to derive the denotation of $\mathrm{CP}_{2}$ of (37). Note how the alternatives introduced by $k i s-k o$ 'who-ACC' are propagated up the tree.

$$
\left\{\lambda i \lambda j . \forall p\left(p \in\left\{\lambda i . \sec ^{\prime}(i)(\operatorname{ravi,y)} \mid y \in \mathscr{E}\} \rightarrow(p(i) \leftrightarrow p(j))\right)\right\}\right.
$$

The same propagation of alternatives can be observed with the alternatives introduced by an in-situ wh-scope marker. This shown in (43) with the denotation derived for $\mathrm{CP}_{1}$ of (37) (where $\mathrm{q}$ is the question intension derived in 42 above). 
(43)

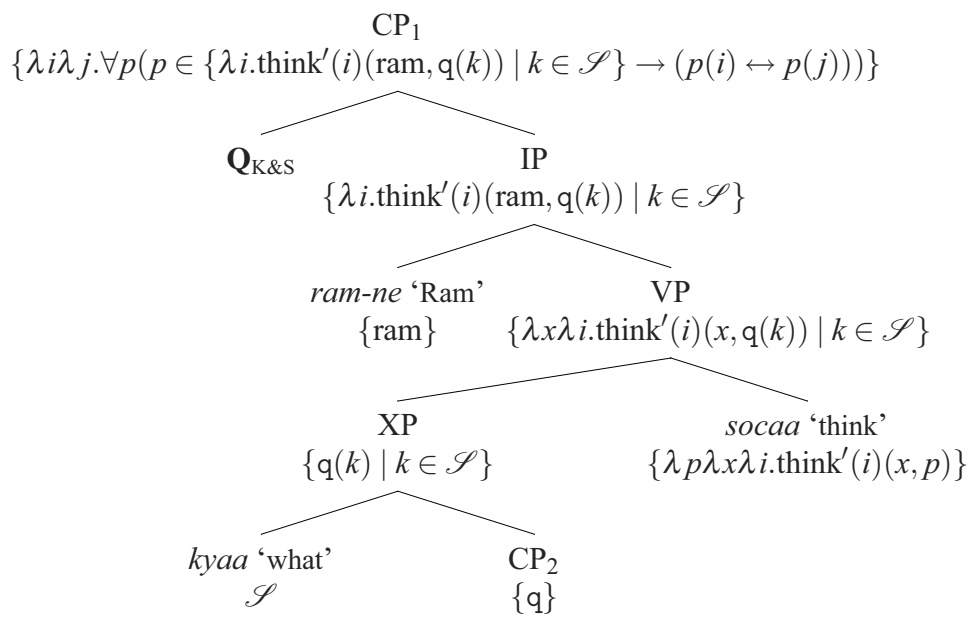

\subsubsection{The ex-situ Interpretation of ex-situ wh-Scope Markers}

For the ex-situ interpretation of ex-situ wh-scope markers (and other ex-situ whphrases), we need to add the rule given in (44), where I assume for simplicity that a moved phrase is coindexed with the variable introduced by the denotation of its trace.

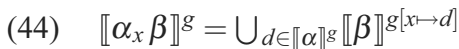

This rule is used in (45) to derive the denotation of $\mathrm{CP}_{1}$ of (1b) (where $\mathrm{q}$ is the intension of $\mathrm{CP}_{2}$ of $1 \mathrm{~b}$ ).

$$
\mathrm{CP}_{1}
$$

$$
\left\{\lambda i \lambda j . \forall p\left(p \in\left\{\lambda i \cdot \operatorname{think}^{\prime}(i)(\text { you, } \mathrm{q}(k)) \mid k \in \mathscr{S}\right\} \rightarrow(p(i) \leftrightarrow p(j))\right)\right\}
$$

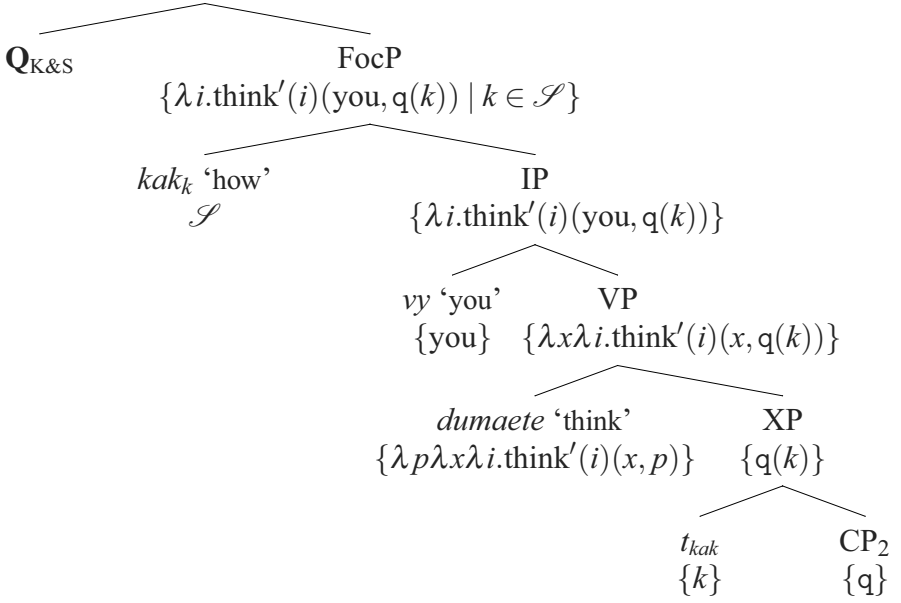




\subsubsection{The Interpretation of Incorporated wh-Scope Markers}

We find $w h$-scope markers incorporated into the matrix verb of a WSM question, for example, in Iraqi Arabic (see Wahba 1991, Stepanov and Stateva 2006):

$$
\begin{aligned}
& \text { sh-tsawwarit Mona meno Ali gabal? } \\
& \text { wsM-thought Mona who Ali met } \\
& \text { 'Who did Mona think Ali met?' }
\end{aligned}
$$

(Iraqi Arabic)

Semantically, the incorporation of an affixal wh-scope marker wSM- can be accounted for by the rule $W I$ defined below (where $q$ is a variable of type $\langle s, s t\rangle$ ).

$$
\begin{aligned}
& \text { If } \llbracket \alpha \rrbracket^{g} \subseteq \mathscr{D}^{\mathscr{D}_{s t}} \text {, then } \llbracket \text { wSM- } \alpha \rrbracket^{g} \subseteq \mathscr{D}^{\mathscr{D}_{\langle s, s t\rangle}} \text { such that } \\
& \llbracket \mathrm{WSM}-\alpha \rrbracket^{g}=\left\{\lambda q \cdot a(q(k)) \mid k \in \llbracket \mathrm{WSM}-\rrbracket^{g} \wedge a \in \llbracket \alpha \rrbracket^{g}\right\}
\end{aligned}
$$

The rule WI applies in the derivation of the denotation of $\mathrm{CP}_{1}$ of (46) shown in (48), where $\mathrm{q}$ is the intension of $\mathrm{CP}_{2}$ of (46). In connection with this rule, I assume that the movement of an affixal $w h$-scope marker does not leave a trace so that the $\mathrm{XP}$ node can be pruned in the LF structure of a scope-marking construction such as (46). ${ }^{15}$ Furthermore, note that in (46) the scope-marker/verb complex is fronted to a clause-initial position. This movement must be reconstructed at LF (see 48).

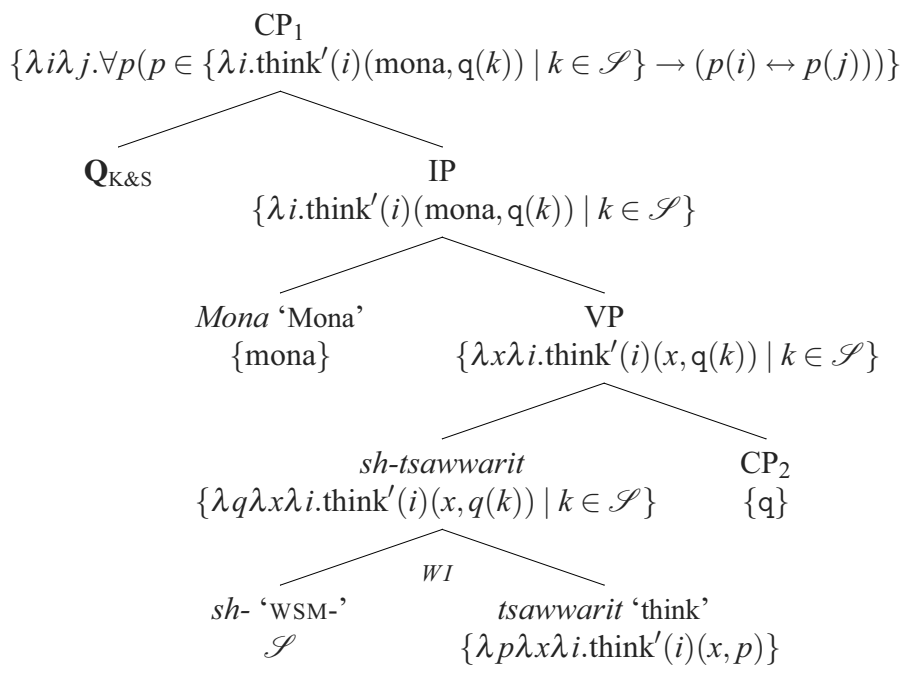

\subsubsection{How the Original IDA Deals with the Typological Diversity}

The original IDA assumes covert phrasal movement of the wh-scope marker in sentences like (37). Wh-intervention effects, however, suggest otherwise. So far, there

\footnotetext{
${ }^{15}$ Alternatively, we could assume that WI is a lexical rule that turns (certain) proposition-taking predicates into question-taking predicates. According to this assumption, the XP layer is not involved in the derivation of (46).
} 
has not been proposed a method for the in-situ interpretation of wh-scope markers for Dayal's IDA. Furthermore, it seems that the original IDA does not make it possible to give a compositional interpretation to incorporated $w h$-scope markers (see Stepanov and Stateva 2006).

\section{Conclusion}

I have presented a variant of Veneeta Dayal's indirect dependency approach to WSM questions. The partition-theoretic IDA presented in this paper derives the correct answerhood conditions for WSM questions and predicts certain aspects of their meaning that require additional assumptions in the original IDA. Furthermore, it was shown that the partition-theoretic IDA is adequate for a number of typologically diverse languages.

\section{Appendix}

In the following, it will be shown that the answerhood conditions of (1b) are correctly represented by $\left(12^{\prime}\right)$ (repeated below in slightly different form).

$$
\begin{gathered}
\lambda i \lambda j\left(\lambda k \cdot \operatorname{think}^{\prime}(i)(\text { you, } \mathrm{q}(k))=\lambda k \cdot \operatorname{think}(j)(\text { you, } \mathrm{q}(k))\right) \\
\text { where } \mathrm{q}(k)=\lambda l\left(\lambda x \cdot \operatorname{love}^{\prime}(k)(\text { ivan, } x)=\lambda x \cdot \operatorname{love}^{\prime}(l)(\text { ivan, } x)\right)
\end{gathered} \quad=: r
$$

It must be shown that for each index $i, r(i)$ is the exhaustive answer to the question of who the hearer thinks that Ivan loves.

Proof: Let i be any index. Assume that (at all indices) the hearer believes a proposition that is an exhaustive answer to q. Furthermore, assume that (at all indices) the hearer believes the consequences of what he believes. Now assume w.l.o.g. that at index $i$, the hearer believes that Ivan loves only Kim. Then $\lambda k$.think ${ }^{\prime}(i)($ you, $q(k)$ ) is the set of indices $\mathrm{k}$ such that $\mathrm{q}(\mathrm{k})$ is the proposition that Ivan loves only Kim. Hence, for all indices $j, \lambda k \cdot \operatorname{think}^{\prime}(i)($ you, $\mathrm{q}(k))=\lambda k \cdot \operatorname{think}^{\prime}(j)($ you, $\mathrm{q}(k))$ iff the hearer believes at index $j$ that Ivan loves only Kim. Consequently, $r(i)$ is the proposition that the hearer believes that Ivan loves only Kim. Since $i$ was chosen arbitrarily, we have proven our claim.

\section{References}

Beaver, David Ian: 2001, Presupposition and Assertion in Dynamic Semantics. CSLI Publications, Stanford, CA.

Beck, Sigrid: 1996, 'Quantified Structures as Barriers for LF Movement', Natural Language Semantics 4, 1-56. 
Beck, Sigrid: 2006, 'Intervention Effects Follow from Focus Interpretation', Natural Language Semantics 14, 1-56.

Beck, Sigrid and Stephen Berman: 2000, 'Wh-Scope Marking: Direct vs. Indirect Dependency', in U. Lutz, G. Müller, and A. v. Stechow (eds.), Wh-Scope Marking, 17-44. Benjamins, Amsterdam.

Dayal, Veneeta: 1994, 'Scope Marking as Indirect Wh-Dependency', Natural Language Semantics 2, 137-170.

Dayal, Veneeta: 1996, Locality in Wh Quantification. Kluwer, Dordrecht.

Dayal, Veneeta: 2000, 'Scope Marking: Cross-Linguistic Variation in Indirect Dependency', in U. Lutz, G. Müller, and A. v. Stechow (eds.), Wh-Scope Marking, 157-193. Benjamins, Amsterdam.

Fanselow, Gisbert and Anoop Mahajan: 2000, 'A Minimalist Theory of WhExpletives', in U. Lutz, G. Müller, and A. v. Stechow (eds.), Wh-Scope Marking, 195-230. Benjamins, Amsterdam.

Groenendijk, Jeroen and Martin Stokhof: 1982, 'Semantic Analysis of WhComplements', Linguistics and Philosophy 5, 175-233.

Groenendijk, Jeroen and Martin Stokhof: 1984, Studies on the Semantics of Questions and the Pragmatics of Answers, Doctoral dissertation, University of Amsterdam, Amsterdam.

Groenendijk, Jeroen and Martin Stokhof: 1994, 'Questions', in J. Van Benthem and A. Ter Meulen (eds.), Handbook of Logic and Language, 1-70. Elsevier, Amsterdam.

Haida, Andreas: 2005, 'Dynamic Wh-Terms', in P. Dekker and M. Franke (eds.), Proceedings of the Fifteenth Amsterdam Colloquium, 95-100. ILLC/Department of Philosophy, University of Amsterdam, Amsterdam.

Hamblin, C.: 1973, 'Questions in Montague English', Foundations of Language 10, 41-53.

Herburger, Elena: 1994, 'A Semantic Difference between Full and Partial WhMovement in German'. Paper presented at LSA Annual Meeting, Boston.

Karttunen, Lauri: 1977, 'Syntax and Semantics of Questions', Linguistics and Philosophy 1, 3-44.

Kratzer, Angelika and Junko Shimoyama: 2002, 'Indeterminate Pronouns: The View from Japanese', in Y. Otsu (ed.), The Proceedings of the Third Tokyo Conference on Psycholinguistics, 1-25. Hituzi Syobo, Tokyo.

Krifka, Manfred: 2001, 'Quantifying into Question Acts', Natural Language Semantics 9, 1-40.

McDaniel, Dana: 1989, 'Partial and Multiple Wh-Movement', Natural Language and Linguistic Theory 7, 565-604.

Pafel, Jürgen: 2000, 'Absolute and Relative. On Scope in German $W h$-Sentences, $W$ - ...W-Constructions', in U. Lutz, G. Müller, and A. v. Stechow (eds.), Wh-Scope Marking, 333-358. Benjamins, Amsterdam.

Pesetsky, David: 2000, Phrasal Movement and Its Kin. MIT Press, Cambridge, Mass.

van Riemsdijk, Henk: 1983, 'Correspondence Effects and the Empty Category Principle', in Y. Otsu et al. (ed.), Studies in Generative Grammar and Language 
Acquisition, 5-16. International Christian University, Tokyo.

Schlenker, Philippe: 2005, 'Non-Redundancy: Towards a Semantic Reinterpretation of Binding Theory', Natural Language Semantics 13, 1-92.

Staudacher, Peter: 2002, 'Partial Movement and Compositionality'. Ms., Universität Potsdam.

Stepanov, Arthur: 1998, 'On Wh-Fronting in Russian', in K. Kusumoto and P. Tamanji (eds.), Proceedings of NELS 28, 453-467. GLSA, Amherst, Mass. Stepanov, Arthur: 2000, 'Wh-Scope Marking in Slavic', Studia Linguistica 54, 140.

Stepanov, Arthur and Penka Stateva: 2006, 'Successive Cyclicity As Residual WhScope Marking', Lingua 116, 2107-2153.

Wahba, Wafaa: 1991, 'LF movement in Iraqi Arabic', in C.-T. J. Huang and R. May (eds.), Logical Structure and Linguistic Structure, 253-276. Kluwer, Dordrecht. 